\title{
A violência institucional contra crianças, adolescentes e suas famí- lias: contexto histórico e perspectivas para a psicologia brasileira
}

\author{
The institutional violence against children, teenagers and their families: historical context and pers- \\ pectives for brazilian psychology
}

Flávio Joni Duarte da Silva ${ }^{\dagger *}$, Maria Clara de Mello Andrade

Como citar esse artigo. da Silva,

F.J.D.; Andrade, M.C.M. A violência institucional contra crianças, adolescentes e suas famílias: contexto histórico e perspectivas para a psicologia brasileira. Revista Mosaico. 2019 Jul./Dez.; 10 (2): SUPLEMENTO 132-137.

\begin{abstract}
Resumo
O presente artigo tem como tema a violência institucional contra crianças, adolescentes e suas famílias. O objetivo do presente trabalho é o de rever conceitos há muito tempo inseridos no imaginário social brasileiro, a saber, o de que crianças e adolescentes não têm direitos ou que seu sofrimento faz parte de sua educação, e que são ainda performados em instituições do Estado. O contexto histórico aqui vislumbrado terá como partida o Código Criminal de 1830, chegando até os dias atuais. A metodologia utilizada para a produção do presente trabalho foi uma revisão bibliográfica nos principais indexadores científicos, utilizando das palavras-chave: violência institucional, infância, políticas públicas. A partir desta filtragem, serão discutidas noções como a de violência institucional contra a infância e a adolescência, entendida por uma perspectiva foucaultiana, suas principais relações com a psicologia e como o profissional psicólogo pode se posicionar diante desta violência praticada pelas próprias instituições em que está inserido.

Palavras-Chave: Violência Institucional, Infância, Políticas públicas.
\end{abstract}

\begin{abstract}
This article deals with institutional violence against children, teenagers and their families. The objective of the present work is to review concepts that have long been inserted in the brazilian social imaginary, like that children and adolescents do not have rights or that their suffering is part of their education, and that they are still performed in State institutions. The historical context here glimpsed will have as a starting, the Criminal Code of 1830, arriving until the present day. The methodology used for the production of the present work was a bibliographical review in the main scientific indexers, using the following keywords: institutional violence, childhood, public policies. From this filtering, notions such as institutional violence against childhood and teenagers will be understood by a foucaultian perspective, its main relations with psychology, and how the professional psychologist can stand in the face of this violence practiced by the institutions in which they are inserted.

Keywords: Institutional Violence, Childhood, Public Policies.
\end{abstract}

\section{Introdução}

O presente artigo tem como intuito rever concepções acerca da violência institucional contra crianças e adolescentes.Entende-se, no presente trabalho, a violência institucional por um viés foucaultiano, relacionando as relações de poder com as verdades produzidas nos discursos, nas instituições, na fala cotidiana, conceitos intrinsecamente ligados dentro da teoria de Michel Foucault. Para Foucault (2017, p. 53) a verdade é "o conjunto das regras segundo as quais se distingue o verdadeiro do falso e se atribui ao verdadeiro efeitos específicos de poder", sendo este último estabelecido nas microrrelações, não mais em sua forma autoritária e de uns contra outros, como no tempo dos grandes reis e rainhas, mas de forma "contínua, ininterrupta, adaptada e 'individualizada' em todo o corpo social". (FOUCAULT, 2017, p. 45) Esta problemática será tratada dentro das principais instituições e saberes que perpassam a infância brasileira, esta sendo aqui entendida como, na proposta do Estatuto da Criança e do Adolescente (BRASIL, 1990), em seu artigo $2^{\circ}$,"criança, [...] a pessoa até doze anos de idade incompletos, e adolescente aquela entre doze e dezoito anos de idade", que necessitam de ajuda em sua formação e desenvolvimento, tanto social quanto

\footnotetext{
Afiliação dos autores: † Graduando de Psicologia, Universidade de Vassouras, Vassouras/RJ, Brasil;
}

¥ Mestre em Psicologia Social, Universidade de Vassouras, Vassouras/RJ, Brasil. 
orgânico.

Perpassa-se, em um primeiro momento, por todo um contexto histórico de criação das primeiras leis com temática referente as crianças, tentando-se demonstrar como foram suas criações e sua visão histórica na época em questão. Em uma segunda parte, centraliza-se as questões relacionadas ao Código de Menores de 1979 e o Estatuto da Criança e do Adolescente. Na terceira parte, compreende-se como a violência institucional está instaurada nos serviços de apoio às crianças e adolescentes - aqui elencados como os serviços de acolhimento, as leis específicas para os jovens, os serviços de medida protetiva- e como a psicologia se torna responsável pelos seus discursos e práticas nesse contexto.

O método utilizado como forma de elaboração foi uma revisão bibliográfica crítica e sustentada pelos direitos humanos, centrando-se em teóricos como Foucault (2017, 2018), Nascimento (2012), Coimbra (2005, 2006), Melim (2015), dentre outros.

A partir de todo um viés histórico, analisado entre o ano de 1830 até a atualidade, tem-se o intuito de tentar entender como as políticas públicas da infância foram construídas, e como essas, ao invés de proteção, puderam praticar a violência institucional, que é, muitas vezes, não notificada e não entendida como violência.

\section{Uma infância em construção: o contexto infantil nos anos anteriores ao surgimento do Estatuto da Criança e do Adolescente}

A infância brasileira atual foi sendo construída durante centenas de anos.O começo de sua elaboração mais aprofundada data do século XIX, onde teve um maior entendimento sobre como e o porquê de a infância dever ser diferenciada do mundo dos adultos.

Por mais que o contexto aqui analisado comece no século XIX, é importante salientar que houveram diferentes infâncias dentro de toda esta linha histórica, que chega até os dias atuais. Entende-se por infância aqui, a já elencada definição do Estatuto da Criança e do Adolescente, mas há uma especificação que deve ser feita. Esta definição não cabia nos tempos passados, e criança, ou pelo menos o jovem que era assim chamado, era o das classes abastadas, sendo o jovem de classe pobre muitas vezes referido como "menor".

Por volta dos anos 1890, a infância começou a entrar em voga nas discussões sociais de forma mais contundente. Com a elaboração do Código Penal de 1890 (BRASIL, 1890), algumas mudanças foram feitas no que concernia à atuação jurídica contra a criança. $\mathrm{O}$ Código Penal antigo, datado de 1830 , preconizava que qualquer criança abaixo de 14 anos poderia ser presa, se tivesse sido provado que esta agiu com discernimento, sendo recolhida para uma casa de correção por tempo determinado por um juiz. (IMPERIO DO BRAZIL, 1830) Santos (2018) assinala as principais diferenças do Código Penal de 1890 para o de 1831 :

O Código Penal da República, bem similar ao antigo, não considerava criminosos os "menores de nove anos completos" e os "maiores de nove anos e menores de 14 que obrarem sem discernimento". A principal mudança residia na forma de punição daqueles que, tendo entre nove e 14 anos, tivessem agido conscientemente, ou seja "obravam com discernimento": deveriam estes ser "recolhidos a estabelecimentos disciplinares industriais, pelo tempo que ao Juiz parecer", não devendo lá permanecer depois dos 17 anos. (SANTOS, 2018, p. 216)

Pode-se notar que a principal mudança estava relacionada à idade para que o aprisionamento fosse instaurado. Com isso, crianças abaixo dos 9 anos não podiam mais ser presas, pois nunca agiam com discernimento, e o aprisionamento das que tinham idades superiores a esta, precisavam ser esclarecidos, pois necessitava-se saber se houve ou não consciência do crime pela criança. É importante salientar que na própria época em questão, o termo "discernimento" era de difícil definição, sendo motivo de inúmeras discussões, tanto no âmbito jurídico quanto no familiar. Vieira (1906, p. 31 apud SANTOS, 2018, p. 217), relata que a definição mais recorrente do termo era "[...] aquela madureza de juízo que coloca o indivíduo em posição de apreciar com retidão e critério, as suas próprias ações".

Em 1927, foi elaborado o primeiro Código de Menores ${ }^{1}$, sendo esta a primeira lei centrada nos direitos das crianças e adolescentes em contexto brasileiro. De forma contrária aos códigos antigos, o novo código declarava que nenhuma criança ou adolescente, menor de 18 anos, poderia ser preso, tendo como forma de reenquadramento na sociedade medidas de assistência e de proteção social. Estes novos parâmetros seguiram "um movimento internacional que iniciou nos Estados Unidos, expandiu-se para a Europa no final do século XIX e, para a América Latina nas primeiras décadas do século XX" (ZANELLA e LARA, 2015, p. 10). Notase então, que o novo código de menores foi elaborado e instaurado tendo como base uma visão internacional, que já vinha se projetando nos continentes mais ricos, e que foi chegando aos poucos no resto do mundo.

Embora houvesse tido mudanças notáveis, o Código de Menores de 1927(BRASIL, 1927)ainda estigmatizava certas crianças, enquadrando-as em categorias como vadios e mendigos. As crianças consideradas vadios eram as que, mesmo vivendo sob tutela ou guarda, de pais ou algum responsável, ignorassem regras e instruções, perambulando habitualmente pelas ruas e locais públicos, ou, além disso, vivessem andando sem rumo pelas ruas tirando seus recursos de ocupações imorais ou proibidas ${ }^{2}$. As crianças que eram consideradas mendigos eram classificadas como as que pediam esmolas de forma 
habitual, para si ou para outro, ou pedissem donativos para venda ou oferecimento de objetos ${ }^{3}$. Vê-se que mesmo com as mudanças propostas, muitas crianças ainda sofriam com essas caracterizações pejorativas, onde, o Código de Menores tivesse o intuito de valer para toda a população, prejudicava muito mais as crianças e famílias de baixa renda.

Conforme Silva (2009), as ideias higienistas presentes na sociedade influenciaram a criação do Código de Menores, indicando que comportamentos diferentes e não aceitáveis deveriam ser combatidos e, como meio de culpabilização, dizia-se que estes comportamentos eram resultados do meio social e de características biológicas hereditárias, culpabilizando a família e a própria criança por seus atos, não havendo crítica alguma ao modo de governo e de como a sociedade era fundamentada. As crianças que eram levadas às instituições de "proteção", eram direcionadas às famílias consideradas aptas ao seu cuidado, esquecendo-se todo o contexto sócio-afetivo-familiar da criança, que "teria uma nova oportunidade".

Salienta-se, novamente, que o termo "menor" era utilizado como referência às crianças pobres, enquanto que para as crianças das famílias consideradas "ideais", este termo não era utilizado, sendo referidas normalmente como crianças. (COSTA, 2012)

Após críticas a esse modelo de "proteção" e de "assistência", o Código de Menores de 1927 foi revisado, criando-se o novo Código de Menores de 1979(BRASIL, 1979).

\section{O Brasil com as crianças: o código de menores de 1979 e o estatuto da criança e do adolescente}

Embora o Código Mello Matos tivesse sido revisto, muitas questões antigas ainda ficaram em aberto. A questão higienista e persecutória com as famílias pobres não se modificou, permanecendo a mesma durante vários anos. (COSTA, 2012; MARAFON, 2014) A sociedade via as crianças pobres e suas famílias como uma ameaça à boa convivência e aos bons costumes, tendo nas políticas públicas da época, no caso o Código de Menores, uma forma de controle e de manipulação da massa. (COSTA, 2012)

Durante esta fase de reestruturação do código, diversos mecanismos institucionais foram criados para tentar lidar com as crianças "delinquentes". Um desses mecanismos foi o chamado Serviço de Assistência ao Menor (SAM), que continuou preconizando o abrigamento e, dentro das instituições a que eram encaminhados os menores por este setor, haviam castigos físicos e uma vigilância severa, pautada em ideias de obediência e de submissão dos jovens. (MELIM, 2015) Críticas a este sistema foram feitas, mas não impediu que outros mecanismos fossem criados. Destes o mais notado e conhecido pela sociedade foi o sistema FUNABEM/FEBEM, que "tinha como meta oficial proteger a criança/adolescente dos 'desajustamentos' sociais e da marginalização, visando integrá-la e ressocializá-la na vida em comunidade." (MELIM, 2015) Sobre o funcionamento deste sistema, Melim (2015) assinala:

\begin{abstract}
As práticas internas da instituição reproduziam a lógica do regime militar vigente na época: repressão, confinamento e violência. Assim, a internação mostrou-se mais uma vez como um sistema degradante e que agravou a situação de milhares de crianças/adolescentes brasileiros, produzindo e reproduzindo entre eles a marginalidade. A questão da assistência à infância passou, com tantas outras coisas, para a esfera de competência do governo militar. Este via na questão social e, no interior desta, na questão do "menor", um problema de segurança nacional, julgando-o, portanto, objeto legítimo de sua intervenção e normalização. (MELIM, 2015, p. 12, grifos do autor)
\end{abstract}

$\mathrm{Na}$ presente citação vê-se como o governo brasileiro se utilizava das crianças e adolescentes como forma de normalizar e intervir na sociedade. Apresentava-se pretextos e atitudes consideradas certas e erradas, que faziam com que crianças pobres fossem levadas à internação muitas vezes com uma promessa de novos caminhos vindouros em seu futuro.Em muitas instituições de "proteção" aos jovens, tanto no passado quanto na atualidade, não há somente a violência simbólica ou de discursos, mas também a física. Há diversos relatos nas mídias de denúncias dos próprios jovens acerca desta situação, como, por exemplo, uma reportagem do G1 (ALMEIDA, 2016), em que uma das falas de um interno é a seguinte: "Jogaram [os instrutores] spray de pimenta em nossas mãos e mandaram a gente passar no rosto e nos olhos. Os instrutores jogavam água na gente para arder mais." Um contexto que, dificilmente, e, lentamente, se modifica.

Após essas diversas "políticas" de cuidado à criança e ao adolescente, foi promulgado, como forma de rechaço a toda esta história conturbada, o Estatuto da Criança e do Adolescente(BRASIL, 1990).Este veio como forma de dar ar ao que antes era hermético e inapropriado. Transforma a criança e o adolescente em sujeitos, tanto de direitos quanto de deveres. Também dá diretrizes para o tratamento a crianças e adolescentes nas instituições públicas, além de também, na instituição familiar. (COSTA, 2012) No Artigo $5^{\circ}$, o ECA diz que "nenhuma criança ou adolescente será objeto de qualquer forma de negligência, discriminação, exploração, violência, crueldade e opressão, punido na forma da lei qualquer atentado, por ação ou omissão, aos seus direitos fundamentais".

Os pontos principais do ECA ganham forma na mudança do termo "menor" para criança e adolescente, tirando o peso pejorativo de toda uma infância regrada 
por padrões e normas, valendo agora não mais somente para as famílias pobres e suas crianças, mas para toda a população; também dá prioridade ao atendimento da criança e do adolescente em diversas instituições públicas. (MELIM, 2015; COSTA, 2012) O ECA adentra a sociedade brasileira como forma de revitalizar uma concepção de criança e adolescente antiga e estigmatizadora, ajudando a todos aqueles que sofrem de violência e maus tratos.

Nota-se, ainda, que o ECA ganha, quase todos os anos, novas atualizações acerca das diretrizes propostas sobre os direitos e deveres de e para com crianças e adolescentes. (IOCHPE, 2015) Com isso, vê-se que houveram algumas mudanças na sociedade, que tenta agora entender e mudar um legado deixado pelas diversas leis que, hoje, são vistas como tendo sido punidoras e violentas. Salienta-se que o ECA não conseguiu resolver todos os problemas, mas adentrou como uma forma de revitalizar as questões pertinentes à infância no Brasil, e mudar o panorama vigente para que novas estratégias e condições de vida para esta parcela da população pudessem ser discutidas e postas em prática.

\section{A violência institucional contra crianças e a psicologia brasileira: a serviço de quem?}

Discutiu-se a violência das instituições passadas, realizadas, muitas vezes pelo próprio Estado. Uma pergunta, no entanto, pode ser feita: como a violência institucional perpassa pelas instituições em que o profissional de psicologia está inserido?

A violência institucional se caracteriza por ser cometida por órgãos e agentes públicos que possuem propósito de defesa e cuidado com os cidadãos, mas não realizam de fato o seu trabalho; utilizam-se de práticas autoritárias, herdadas de tempos passados, tendo como intuito um controle social da população pobre. (ILANUD, 2013) Como viu-se anteriormente, essas práticas parecem ser intrínsecas à sociedade brasileira, sendo uma ação diretiva do próprio Estado, modificando o real pela sua própria vontade e interesse, através de discursos e práticas que formam uma verdade e alicerçam poderes, legitimando certas práticas enquanto rechaça outras.

Esta prática de violência afeta muito mais a população pobre, onde há um desconhecimento maior de seus próprios direitos, fazendo com que seu panorama sócio-histórico-cultural continue a ser o mesmo. (ILANUD, 2013) É importante salientar que este desconhecimento acaba, muitas vezes, por ser proposital por parte dos governantes, mantendo assim o status quo da sociedade.

Mas como esta violência configura-se na prática?
Ela se mostra na presença de diversos mecanismos sociais como a negligência, a maioridade penal, a permanência em instituições por um tempo demasiadamente longo, terminando por não se respeitar os direitos fundamentais das crianças e sua história sócio-afetiva-familiar. (ILANUD, 2013; COIMBRA e NASCIMENTO, 2005) Também há a violência física, encontrada em diversas instituições de reenquadramento social.

Segundo o ILANUD (2013), a negligência passa pelo descuido do próprio Estado em dar condições necessárias ao abrigamento com dignidade e com bons fatores sociais. Pesquisas realizadas por esse mesmo órgão, mostraram que em diversas instituições de abrigamento infantil, havia "um desleixo por parte da instituição, má qualidade de suas habitações físicas, carência de pessoal e, entre outras características, ausência de processo educativo." (ILANUD, 2013, p. 4) Salienta-se que, nestes espaços, há a atuação do profissional de psicologia, e que seu código de ética foi formulado tendo como base os Direitos Humanos Universais. Uma das responsabilidades do profissional psicólogo é lutar para que estas situações não ocorram e se modifiquem.

Sobre a maioridade penal,esta é vista como um mecanismo de "bode expiatório". Culpa-se o adolescente de forma exacerbada por crimes cometidos que, em grande parte, são roubos e furtos ${ }^{4}$, que perpassam por uma camada social deixada de lado, e que precisa, de alguma forma, conseguir permanecer vivendo. Salienta-se ainda que a impunidade, vista como inerente ao adolescente infrator pela sociedade, não acontece de fato, estes recebendo "medidas socioeducativas compatíveis com a sua condição de pessoa em desenvolvimento e ao fato delituoso em que se envolveu." (ILANUD, 2013, p. 3) Inclui-se também a ideia de que a sociedade passa para o jovem pobre e de baixa renda culpas que servem para tirar de si própria a responsabilidade por questões relacionadas ao crime infantil. Em uma sociedade tão desigual como a brasileira, a criança pobre é vista por fora, como um duplo, associada à marginalidade, à criminalidade e à violência. (COIMBRA e NASCIMENTO, 2005)

Outra forma de violência institucional é a transformação de abrigos e instituições de acolhimento em local de moradia. Retira-se o jovem de sua família de origem, e também de sua família extensa, colocando sobre estes o estigma de "família negligente", tentando enquadrá-los no ideal familiar. (ILANUD, 2013; IOCHPE, 2015; NASCIMENTO, 2012) Mas que ideal é este? Esquece-se toda a configuração de comunidade, de espaço e de território, além, do mais importante, questões afetivas e emocionais da criança para com seus familiares. Podem existir situações em que o abrigamento é necessário, e que familiares e responsáveis são realmente negligentes e abandonam suas crianças. (ILANUD, 2013) Especificamente nestes 
casos o abrigo se torna essencial, mas não se deve deixar de lado o direito da criança conviver com seus familiares, tanto nuclear quanto extensos, além de ter uma boa qualidade de vida, tanto na sociedade em que vive quanto nas instituições de abrigamento, quando for necessário seu acolhimento.

A violência institucional é um sério problema público, pois ela aparece como defeito doEstado que deveria ajudar, mas acaba legitimando práticas eugenistas e espetaculares, criando nas famílias consideradas "ruins" um sentimento de vulnerabilidade e de angústia por não conseguir proporcionar o "correto e o benéfico" para seus integrantes. Isso acaba por acontecer quando os profissionais destas instituições não se vinculam ao fator social e assistencial, criando verdades que vão de contramão ao que beneficiaria a população. Coimbra e Nascimento (2005) analisam o século XX até os dias de hoje, afirmando que dispositivos sociais produzem subjetividades "corretas", padronizadas, modelando famílias e sujeitos, ligando-os a ideias de perigo, que acabam por thes afastar da sociedade em que vivem. Isto é reforçado pela ideia foucaultiana de poder, que se vincula a verdades recorrentes no meio social, criando discursos capazes de legitimar práticas e atitudes.

E como esta violência perpassa pela psicologia? Esta está inserida em organizações de proteção social. A todo momento existem demandas para dar discursos estigmatizantes, classificatórios e coniventes com as vozes dominantes. (COIMBRA, 2006) O papel da psicologia aqui pode ser entendido como o de entender estas demandas, para que não sejam repetidas sem uma teorização crítica e alicerçada pelos saberes psicológicos.

Sabe-se, através de diversos relatos históricos, que a psicologia brasileira foi, em diversos momentos, concomitante com ideais que hoje são vistas como atrocidades. Sobre isto, o referencial de Zuquim (2001) é esclarecedor, demonstrando como a psicologia foi utilizada como meio de propagação de ideias sociais racistas e classificatórias, compactuando com opiniões, que, hoje, vão em contramão aos direitos humanos e aos direitos sociais de cada sujeito. Há ainda que se destacar a história dos intelectuais brasileiros, que estiveram, muitas vezes, permeados por ideias, atualmente, vistascomo preconceituosas, enxergando as pessoas pobres como não dignas de educação e condições de vida, tendo estas que se adaptar da melhor maneira possível à sociedade em que viviam, onde, esta adaptação, se transformava em marginalização da própria pessoa, uma exclusão incluidora. (SAWAIA, 2014)

A psicologia se cria e se transforma no momento em que está inserida na realidade, e, quando ligada com a proteção social, precisa-se ainda mais discutir esta realidade em sua volta, exigindo reflexões da estrutura da sociedade, uma visão de mundo que abranja todas as relações e vivências econômicas, culturais e sociais.
(MELIM, 2015) Se isto falta, acaba-se por perder a força de trabalho, a demanda do sujeito, sendo esta confundida com demandas quepodemnão caber à psicologia, demandas não humanitárias e de cunho institucional. Estas demandas serviriam como governos, uma condução de condutas que teria como finalidade a manipulação dos corpos e do intelecto da massa, criando, por conseguinte, um aglomerado de ações possíveis e requeridas, apropriadas e não apropriadas. (CASTRO, 2017, p. 112 apud FOUCAULT, 1994, t. IV, p. 237)

As relações de poder se mostram na prática de discursos, contrários muitas vezes, mas que detém em seu simbolismo ideologias dominantes e dominadas, onde a intenção de alguém com um suposto saber deve ser interrogá-lo, desmembrá-lo, para que este se transforme na prática e instrumentalize os que precisam de direito. (FOUCAULT, 2018) Mas, além disso, é dar aos próprios sujeitos a possibilidade de conhecerem seus direitos, de se ressignificarem partindo do conhecimento das leis e diretrizes que regem suas vidas, e, para isso, o profissional de psicologia precisa sair deste lugar de saber, de saber sobre o outro, para adentrar o de que o outro sabe sobre si mesmo, e tem direito de lutar pelos seus próprios desejos e anseios.

\section{Considerações finais}

Viu-se, partindo de um contexto histórico de criação de leis para o "cuidado" com os jovens que, em sua maioria, vistos a partir da visão humanitária que se tem atualmente, foram dispositivos de controle e de culpabilização da família pobre. A psicologia estava inserida em todo este contexto, utilizando-se dos testes psicológicos e das teorias de classificação de cunho darwinista, hoje vistos como de ideias eugênicas e preconceituosas.

Uma Psicologia sem cuidado, sem pensar a si própria, pode sustentar discursos dominantes, indo de contramão com todos os preceitos éticos da profissão. Sendo assim, adentra no mundo social, no mundo infantil, trabalhando com um viés protetivo, podendo inibir a produção de sujeitos, que é o princípio fundamental da profissão.

Tutelar não é cuidar, e dizer o que é certo e errado é se omitir das próprias finalidades do discurso posto em voga. Quando esta omissão ocorre, está-se deixando de criar possibilidades, e adentrando um discurso de cunho social que não deve ser tido como a única verdade. $\mathrm{O}$ saber da psicologia é, muitas vezes, construído a partir da demanda do outro, e é só a partir dessa demanda que se pode deixar o outro surgir, se colocar. Tratar e ajudar crianças e adolescentes pode ser uma tarefa difícil, ainda mais dentro de instituições governamentais, que perpassam a todo momento por questões eugenistas e preconceituosas. 
Portanto, as (os) psicólogas (os) podem tentar servir como forma de tornar estas crianças sujeitos da própria história, mostrando-lhes que existem outras saídas sem ser aquelas impostas, advertidas e de cunho preconceituoso. Pode haver a saída de lutar por si próprio, usando da própria história como alavanca para um futuro mais promissor, indo de contramão a tudo que foi imposto, omitido e justificado por outros.

\section{Notas}

1. Também chamado de Código Mello Mattos, em homenagem ao seu autor, José Cândido de Albuquerque Mello Mattos, sendo este o $1^{\circ}$ juiz de Menores do Brasil. (AZEVEDO, s.d., p. 3)

2. Artigo 28, do Código Penal de 1927. (BRASIL, 1927)

3. Artigo 29, do Código Penal de 1927. (BRASIL, 1927)

4. Em pesquisa realizada no site do Cadastro Nacional de Adolescentes em Conflito com a Lei (CADASTRO, s.d.), em todo o ano de 2018, houveram cerca de 12.063 casos de Furto (Furto Qualificado, Furto previsto no art. 155, Furto Privilegiado e Furto de Coisa Comum) e 35.609 casos de Roubo (Roubo previsto no art. 157, Roubo Majorado e Roubo Qualificado), que se somados (47.672), passam os casos de Tráfico de Drogas (30.335), tido como $\mathrm{o}$ ato infracional de maior incidência entre os adolescentes.

\section{Referências bibliográficas}

ALMEIDA, V. Jovens infratores relatam torturas e maus-tratos em centros do Ceará. G1,2016. Disponível em:<http:/g1.globo.com/ceara/noticia/2016/05/ jovens-infratores-relatam-torturas-e-maus-tratos-em-centros-no-ceara. html>. Acesso em: 26 maio 2019

AZEVEDO, M. M. O Código Mello Mattos e seus reflexos na legislação posterior. (s.d.). Disponível em: <http://www.tjrj.jus.br/ documents/10136/30354/codigo_mello_mattos_seus_reflexos.pdf $>$. Acesso em: 24 maio 2019.

BRASIL, Decreto $n^{\circ}$ 847, de 11 de outubro de 1890. Código Penal dos Estados Unidos do Brazil. Rio de Janeiro, RJ.

BRASIL, Decreto n ${ }^{\circ}$ 17.943-A, de 12 de outubro de 1927. Código dos Menores. Brasília, DF.

BRASIL, Lei $n^{\circ}$ 6.697, de 10 de outubro de 1979. Código de Menores. Brasília, DF.

BRASIL. Lei n ${ }^{\circ} 8.069$, de 13 de Julho de 1990. Estatuto da Criança e do Adolescente. Diário Oficial da União, Brasília, DF.

CADASTRO Nacional de Adolescentes em Conflito com a Lei. CNJ, (s.d.). Disponível em: $<$ https://www.cnj.jus.br/cnaclnovo/publico/>. Acesso em: 26 maio 2019.

CASTRO, E. Introdução a Foucault. Belo Horizonte: Autêntica Editora, 2017.

COIMBRA, C. M. B.; NASCIMENTO, M. L. Ser jovem, ser pobre é ser perigoso? JOVENes, Revista de Estudios sobre Juventud, ano 9, 22, 338355. 2005. Disponível em: <https://app.uff.br/slab/uploads/texto23.pdf $>$. Acesso em: 26 maio 2019.

COIMBRA. C. M. B. Direitos humanos e Criminalização da Pobreza. In: I Seminário Internacional de Direitos Humanos, Violência e Pobreza: a situação de crianças e adolescentes na América Latina hoje. 2006, Rio de Janeiro, UERJ. Disponível em: <http://www.aedmoodle.ufpa.br/pluginfile. $\mathrm{php} / 174600 / \mathrm{mod}$ resource/content $/ 1 / 5 . \% 20$ Direitos $\% 20$ Humanos $\% 20$ e\%20Criminaliza $\%$ C $3 \%$ A $7 \%$ C $3 \%$ A30\%20da $\% 20$ Pobreza.pdf $>$. Acesso em: 12 mar. 2019.

COSTA, A. C. P. As políticas de proteção a infância e adolescência e a educação: reflexões a partir da década de 1920. In: IV CONGRESSO INTERNACIONAL DE PEDAGOGIA SOCIAL, 4., 2012, São Paulo. Proceedings online...Associação Brasileira de Educadores Sociais, Disponível em: <http://www.proceedings.scielo.br/scielo.php?script=sci a
rttext\&pid=MSC0000000092012000100003\&lng=en\&nrm=abn>. Acesso em: 13 mar. 2019.

FOUCAULT, M. História da Sexualidade: a vontade de saber. 7. ed., São Paulo: Editora Paz e Terra, 2018.

FOUCAULT, M. Microfísica do Poder. 5 ed., Rio de Janeiro: Editora Paz e Terra, 2017.

ILANUD. Violência institucional: quando o estado agride a criança. (s.1.). Versão 1.0, Brasil: Instituto Latino-Americano das Nações Unidas para Prevenção do Delito e Tratamento do Delinquente, 2013. Disponível em: $<$ http://www.tjpe.jus.br/documents/72348/118271/ILANUD_Viol\%C3\%A Ancia+institucional+quando+o+estado+agride+a+crianca.pdf/4b026a2c5c91-4e4d-9ff0-3adb12c1d77a> Acesso em: 24 maio 2019.

IMPERIO DO BRAZIL. Lei de 16 de Dezembro de 1830. Código Criminal do Imperio do Brazil. Rio de Janeiro, RJ.

IOCHPE, E. L. A psicologia e o acolhimento institucional: histórias, práticas e lugares. Universidade Federal do Rio Grande do Sul, Instituto de Psicologia, Trabalho de Conclusão de Curso. Porto Alegre, 2015.

MARAFON, G. Judicialização da infância: da menoridade à prevenção do bullying. Revista entreideias, v. 3. n. 1, p. 79-93. 2014.

MELIM, J. I. Trajetória da proteção social brasileira à infância e à adolescência nos marcos das relações sociais capitalistas. Serviço Social e Saúde, Campinas, SP, v. 11, n. 2, p. 167-184, maio 2015. Disponível em: <https:// periodicos.sbu.unicamp.br/ojs/index.php/sss/article/view/8635161>. Acesso em: 15 mar. 2019

NASCIMENTO, M. L. Abrigo, pobreza e negligência: percursos de judicialização. Psicologia \& Sociedade, 24, n. spe., 39-44. 2012. Disponível em: <http://www.scielo.br/pdf/psoc/v24nspe/07.pdf>. Acesso em: 26 maio 2019.

SANTOS, M. A. C. Criança e criminalidade no início do século XX. In: DEL PRIORE, M. (Org.). História das crianças no Brasil. 7. ed., São Paulo: Contexto, 2018.

SAWAIA, B. (Org.). As artimanhas da exclusão: análise psicossocial e ética da desigualdade social. 14. ed., Petrópolis: Editora Vozes, 2014.

SILVA, C. G. P. P. Código Mello Mattos: um olhar sobre a assistência e a proteção aos "menores". Revista Em Debate, no 8, 2009. Disponível em: $<$ https://www.maxwell.vrac.puc-rio.br/14406/14406.PDF>. Acesso em: 12 mar. 2019.

ZANELLA, M. N.; LARA, A. M. O Código de Menores de 1927, o direito penal do menor e os congressos internacionais. USP - Ano VI, n. 10, p. 105128,2015 .

ZUQUIM, J. Infância e crime na história da psicologia no Brasil: Uma análise de categorias psicológicas na construção histórica da infância criminalizada na Primeira República. São Paulo, 2001. 216 p. Tese de Doutorado. Instituto de Psicologia, Universidade de São Paulo. 